\title{
PARTICIPAÇÃO, ACESSIBILIDADE DIGITAL E A INCLUSÃO DA PESSOA COM DEFICIÊNCIA
}

\author{
Flávia Piva Almeida Leite ${ }^{1}$ \\ Caroline Kraus Luvizotto ${ }^{2}$
}

\section{Resumo:}

O objetivo desse artigo é discutir acerca da participação e acessibilidade digital das pessoas com deficiência no Brasil, com vistas a sua inclusão social. Parte do cenário da sociedade da informação, refletindo sobre o conceito de participação e participação on line, apresentando uma problematização sobre a inclusão desses sujeitos, para, finalmente, discutir a acessibilidade digital para a pessoa com deficiência na Lei Brasileira de Inclusão. Concluiu-se que, somente a normatividade dos direitos não é o bastante para garantir a implementação de ações para efetivar a acessibilidade de modo real e palpável às pessoas com deficiência no universo digital.

\section{Palavras-chave:}

Pessoa com deficiência; Acessibilidade digital; Participação; Lei Brasileira de Inclusão; Inclusão social

\section{PARTICIPATION, DIGITAL ACCESSIBILITY AND THE INCLUSION OF THE DISABLED PERSON}

\begin{abstract}
:
The objective of this article is to discuss the participation and digital accessibility of disabled person in Brazil, with a view to their social inclusion. Part of the information society scenario, reflecting on the concept of online participation and participation, presenting a problematization about the inclusion of these subjects, to finally discuss digital accessibility for the disabled with the Brazilian Inclusion Law. It was concluded that only the normativity of the rights is not enough to guarantee the implementation of actions to effect the accessibility in a real and palpable way to people with disabilities in the digital universe.
\end{abstract}

\section{Keywords:}

Disabled person; Digital accessibility; Participation; Brazilian Inclusion Law; Social inclusion

\footnotetext{
${ }^{1}$ Doutora em Direito Urbanístico pela Pontifícia Universidade Católica - PUC - São Paulo/SP, Mestre em Direito Constitucional pela Instituição Toledo de Ensino - ITE - Bauru/SP, Pós-graduada em Gerente de Cidades pela Fundação Armando Álvares Penteado - FAAP - São Paulo/SP. Docente da UNESP - Universidade Estadual Paulista "Julio de Mesquita Filho", Faculdade de Arquitetura, Artes e Comunicação - Campus Bauru. Docente permanente do Programa de Pós-Graduação em Direito da UNESP. Avaliadora do CONPEDI. E-mail: <flavialeite@faac.unesp.br>.

2 Doutora, Mestre e Bacharel em Ciências Sociais pela UNESP. Docente da UNESP - Universidade Estadual Paulista "Julio de Mesquita Filho", Faculdade de Arquitetura, Artes e Comunicação - Campus Bauru. Docente permanente do Programa de Pós-Graduação em Comunicação da UNESP. Avaliadora do CONPEDI. E-mail: <caroline@faac.unesp.br>.
} 


\section{Introdução}

Vivemos em uma sociedade baseada essencialmente no desenvolvimento e na disseminação das tecnologias e da comunicação.

Presenciamos, assim, a sociedade da informação, ou sociedade da comunicação, como prefere denominá-la o professor José de Oliveira Ascensão (1999, 163-184), ou ainda sociedade do conhecimento, como revela o filósofo Pierre Lévy, um dos autores de maior envergadura a respeito da matéria ${ }^{3}$. Do mesmo modo como a Revolução Industrial modificou as feições do mundo, a ainda incipiente Revolução Digital certamente irá transformar as faces do planeta.

O surgimento dessa nova sociedade trouxe, portanto, a necessidade de se repensar importantes aspectos relativos à organização social e o papel do Estado nesse novo contexto. Destaque deve ser dado para o uso das tecnologias da internet para fins de participação e de inclusão social.

Muitas ações de caráter político-social se fortaleceram e se potencializaram à medida em que a internet deu suporte a elas, utilizando sua arquitetura em rede para disseminar informação e promover a discussão coletiva. A partir dessa ferramenta foi possível propor e organizar ações e ampliar os canais de participação.

A participação é uma ação social coletiva que possui em sua gênese uma série de características, dentre as quais, podemos destacar suas estratégias de ação, sua organização, a historicidade, os laços e identidades compartilhadas. Essas características somadas a um projeto de sociedade é que levam os atores sociais a se aproximarem dessas ações coletivas e atuarem ativamente ou ocasionalmente junto aos movimentos sociais, aos espaços de

\footnotetext{
${ }^{3}$ Pierre Lévy escreveu os seguintes livros já traduzidos para o nosso vernáculo: As tecnologias da inteligência: o futuro do pensamento na era da informática. Rio de Janeiro, Editora 34, 1993; As árvores de conhecimentos. São Paulo: Escuta, 1995 (em coautoria com Michel Authier); O que é o virtual? São Paulo: Editora 34, 1996; A ideografia dinâmica: para uma imaginação artificial? Lisboa: Instituto Piaget, 1997; A ideografia dinâmica: rumo a uma imaginação artificial? São Paulo: Loyola, 1998; A máquina universo: criação, cognição e cultura informática. São Paulo: Artmed, 1998; Cibercultura. Tradução de Carlos Irineu da Costa. São Paulo: Editora 34, 2001; A inteligência coletiva: por uma antropologia do ciberespaço. 3. ed. São Paulo: Loyola, 2000; Filosofia world: o mercado, o ciberespaço, a consciência. Lisboa: Instituto Piaget, 2000; A Conexão Planetária: o mercado, o ciberespaço, a consciência. São Paulo: Editora 34, 2001; Ciberdemocracia. Lisboa: Instituto Piaget, 2003; O futuro da internet. São Paulo: Paulus, 2010; O fogo liberador. São Paulo: Iluminuras, 2007. Neles fica absolutamente transparente que se trata de um dos maiores estudiosos da vida digital, analisando o fenômeno da internet sob uma perspectiva claramente humanista.
} 
deliberação política e aos mais diversos contextos onde se faz necessária uma ação democrática e cidadã.

Pode-se afirmar que as ações coletivas são sadias dentro de um ambiente político e social plural como o brasileiro e projetam atores políticos que passam a exigir do poder público a efetivação de direitos civis, políticos e sociais garantidos por lei. Trata-se de um componente advindo do amadurecimento das democracias. "A mudança no entendimento da organização e ação dos coletivos sociais ocorreu, em grande parte, em decorrência das transformações no cenário político internacional”, destaca Machado (2007, p. 254), que salienta a intensificação de forças verificada quando, “com o fim da guerra fria e o surgimento da simbiose entre democracia ocidental e capitalismo, os movimentos sociais passaram gradualmente a ser considerados atores sociais importantes para a promoção dos direitos civis e da cidadania" (MACHADO, 2007, p. 254).

Partindo dessa premissa básica a questão da inclusão das minorias étnicas, sociais, culturais e de gênero tomou relevo e passou a ser reconhecida em documentos nacionais e internacionais. Esse novo paradigma social trouxe como princípios o reconhecimento e a valorização da diversidade humana, a solidariedade humanitária, a igual importância desses grupos, o que motivou as pessoas com deficiência a se organizarem e promoverem um forte movimento de participação política e social no âmbito do processo de redemocratização do Brasil.

Diante desse contexto, o objetivo desse trabalho é discutir acerca da participação e acessibilidade digital das pessoas com deficiência no Brasil, com vistas a sua inclusão social.

Nessa perspectiva, a Constituição Federal de 1988 inaugurou novas feição e estrutura ao Estado brasileiro, uma vez que não somente o consagrou democrático, mas também ressaltou o seu caráter essencialmente social, ao fundá-lo em valores como a dignidade humana e a cidadania, que repercutem sobre o ordenamento como um todo e ao mesmo tempo serve de norte para toda e qualquer iniciativa privada e pública.

Ademais, o Brasil, na busca pela concretização dos direitos das pessoas com deficiência, inclusive quanto à acessibilidade aos meios de comunicação e às novas tecnologias, assinou, em 30 de março de 2007, a Convenção Internacional sobre os Direitos das Pessoas com Deficiência e seu Protocolo Facultativo, no âmbito da Organização das 
Nações Unidas. A sua aprovação pelo Congresso Nacional ocorreu por meio do Decreto Legislativo 186/2008, tendo sido promulgada pelo Decreto 6.949, de 25 de agosto de 2009.

Para concretizar os direitos das pessoas com deficiência, foi promulgada no Brasil a Lei 13.146, de 06 de julho de 2015, tendo instituído a Lei Brasileira de Inclusão da Pessoa com Deficiência (Estatuto da Pessoa com Deficiência), que em seu título III, assegura o direito à acessibilidade aos meios de informação e comunicação, inclusive de sistemas de tecnologias da informação e comunicação e de outros serviços.

Este artigo parte do cenário da sociedade da informação para abordar a temática da acessibilidade digital da pessoa com deficiência, a partir de uma reflexão que se inicia com o conceito de participação e participação online, apresentando uma problematização sobre a inclusão desses sujeitos, para, finalmente, discutir a acessibilidade digital para a pessoa com deficiência na Lei Brasileira de Inclusão. A abordagem metodológica se caracteriza por ser de cunho exploratório, descritivo e analítico, baseado na revisão da literatura pertinente sobre o tema e na análise documental e jurídica.

\section{Participação na Sociedade da Informação}

A participação está intimamente ligada à cidadania e vai mudar de acordo com a possibilidade de atingir diferentes sujeitos sociais que se identificam com determinada causa, ou simplesmente têm consciência de seu papel como cidadãos e têm a necessidade de participar. Para Bordenave (1983, p. 23), "participação é fazer parte, tomar parte ou ter parte". Para ele, de nada adianta "fazer parte" sem "tomar parte", como por exemplo, alguém que faz parte de um grupo, mas não toma parte das decisões do grupo. A participação está ligada à atividade e ao engajamento. A participação seria inata ao ser humano devido às suas necessidades criativa e racional e a democracia seria um estado da participação (BORDENAVE, 1983).

O Brasil é marcado por uma história recente de ditadura militar. Estamos aprendendo a viver em democracia e esse não é um processo rápido, tampouco simples. É verdade, porém, que hoje o povo brasileiro tem maior poder de participação, mas a herança da ditadura ainda 
se faz presente, contrastando com a busca pela democracia efetiva. Neste sentido, pode-se dizer que a participação é um mecanismo de fortalecimento do convívio em sociedade.

Para Demo (1996, p. 19-20) "participação supõe compromisso, envolvimento, presença em ações por vezes arriscadas e até temerárias". Com efeito, pode-se afirmar que o exercício da cidadania passa diretamente pela participação de um povo e suas demandas. De acordo com o autor, participação é um processo e uma conquista e nesse sentido está "em constante vir-a-ser, sempre se fazendo" (DEMO, 1996, p. 18). Demo também afirma que por meio da participação seria possível o Estado e a sociedade civil governarem juntos o país, os estados e os municípios, pois, segundo ele, "participação, por conseguinte, não é ausência, superação, eliminação do poder, mas outra forma de poder" (DEMO, 1996, p. 18).

De acordo com Fonseca (2011, p. 70), os meios de comunicação mobilizam opiniões com o objetivo de "[...] difundir informações, estimular os vínculos de solidariedade, favorecer os laços de identidade e promover o engajamento e a co-responsabilidade, no sentido de articular os sujeitos e estimular a participação [...]”. Porém, o papel dos meios de comunicação no cenário da participação política e social aumentou e ganhou maior ressonância com o advento da internet e de suas ferramentas da web 2.0.

É possível notar que as gerações atuais exercem parte de seus direitos expressivos por meio da internet. A web 2.0 serve de grande atrativo para a articulação dos movimentos sociais, dos ativistas e dos cidadãos em geral, pois nela é possível a interação coletiva por intermédio de comunidades formadas em torno de interesses específicos, dar apoio a causas, além de discutir temas individuais ou temas de relevância coletiva, levando assim a opinião pública a reflexão e disseminar informações políticas e sociais (LUVIZOTTO, 2016).

A relação entre participação e os meios de comunicação já foi debatida e estudada por diversos autores, entre eles Joaquim Paulo Serra que estabeleceu três modalidades de participação:

a) Participação política nos media: "os media como a arena em que se desenvolve (e em que se assiste) a luta política, a luta entre os argumentos e contra-argumentos dos vários atores políticos" (SERRA, 2012, p.129). O autor considera essa uma modalidade dialética; 
b) Participação política através dos media: "os media usados como meios para atingir uma determinada audiência, que se pretende influenciar num ou noutro sentido", considerada uma modalidade retórica (SERRA, 2012, p.129);

c) Participação política para os media: "os media como o ecrã que torna visível (isto é, "real”) o espetáculo da política”, a modalidade cênica (SERRA, 2012, p.129).

Em complemento a essas modalidades, refletindo especificamente sobre a internet, podemos citar Gomes, que, em 2005, abordou as expectativas para esse meio de comunicação. De acordo com o autor, "quase todas as formas de ação política por parte da esfera civil podiam agora ser realizadas mediante a internet", ações como "contato e pressão sobre os representantes eleitos, até a formação da opinião pública, engajamento e participação em discussões sobre os negócios públicos até a afiliação a partidos ou movimentos da sociedade civil" podiam ser realizados com o auxílio das ferramentas da web 2.0 (GOMES, 2005, p. 64). Destaca, ainda, outras ações de caráter político-social que poderiam ser potencializadas na internet: "manifestação à mobilização, da interação com candidatos até a doação para fundos partidários ou de organizações civis, da intervenção em fóruns eletrônicos sobre matéria da deliberação da sociedade política até a intervenção em plebiscitos on-line" (GOMES, 2005, p. 64).

A expectativa era bastante favorável, uma vez que o meio utilizado, a internet, possui ferramentas que possibilitam essas ações. Porém, para que esse tipo de participação se efetive é preciso que haja uma cultura de participação, uma educação para a cidadania e mecanismos de mobilização social offline, ou seja, fora da internet.

Refletindo sobre mobilização social, destaca-se Scherer-Warren que apresenta uma organização da sociedade civil mobilizada em três níveis:

- O primeiro nível - associativismo local: movimentos comunitários e as próprias ONGs que lutam por "causas sociais ou culturais do cotidiano" (SCHERER-WARREN, 2006, p. 110). Como exemplo desse nível, a autora destaca os núcleos dos movimentos sem terra, sem teto, piqueteiros, empreendimentos solidários e associações de bairro.

- O segundo nível - organizações inter-organizacionais: "fóruns da sociedade civil, as associações nacionais de ONGs e as redes de redes" (SCHERER-WARREN, 2006, p. 
111), que se articulam para empoderar a sociedade civil. Nesse nível, ocorre a mediação necessária para parcerias mais institucionalizadas entre a sociedade e o Estado.

- O terceiro nível - mobilização na esfera pública: a articulação de todos estes atores sociais que buscam algo além da organização institucional conciliatória e partem para grandes manifestações, tendo em vista visibilidade midiática e exercer pressão política (SCHERER-WARREN, 2006, p. 111). Como exemplo do terceiro nível indica-se a Marcha das Vadias, a Parada do orgulho LGBTT, e as próprias Manifestações de Junho de 2013 no Brasil em um nível ainda mais extremo.

Com a internet e as mídias digitais, as formas de comunicação e consumo de informação se modificaram, deixando de ser unilaterais - marca dos meios de comunicação de massa - e passam a ser mais participativas e democráticas. Mesmo que de maneira limitada, considerando os problemas de acesso à rede, acessibilidade, usabilidade e conhecimento do usuário, a internet possibilita participação e interação entre os indivíduos, sendo uma forma de comunicação rápida, prática e sem barreiras geográficas. Esse ambiente online modificou a maneira como sujeitos e grupos sociais manifestam as suas demandas políticas e sociais. Os recursos e ferramentas tecnológicas de informação foram aprimorados rapidamente, democratizando de maneira inédita o acesso à informação. Com o advento da internet e das ferramentas da web 2.0, a informação deixa de se concentrar na mídia de massa e nos grandes conglomerados midiáticos e se oferece a possibilidade de produção, seleção e interação aos seus usuários, gerando novos conteúdos e fontes de informação. Hoje, ONGs, movimentos sociais e ativistas podem propagar suas ideias para todo o mundo, oferecendo a informação à sua maneira. Agências de notícias alternativas e independentes surgem para contestar as versões da imprensa tradicional, como é o caso da mídia Ninja, Jack Mídia Independente e diversos blogs e websites contra-hegemônicos.

Neste cenário, destaca-se a presença de movimentos sociais que sempre estiveram presentes na sociedade, atuando e mobilizando a sociedade civil por causas sociais, ambientais, culturais, políticas e econômicas, dentre muitas outras. Nesse estudo, não podemos deixar salientar o importante papel desempenhado pelas pessoas com deficiência 
que vem se organizando em movimentos sociais, ativistas, ganhando ressonância nacional. Trataremos desse tema logo a seguir.

O avanço tecnológico e o desenvolvimento das tecnologias de informação e comunicação permitiram a aproximação dos diversos ativistas e movimentos sociais das pessoas com deficiência com seus apoiadores e uma nova forma de se manifestar. A internet e o ciberespaço possibilitaram que especialmente essas pessoas de qualquer lugar do mundo, que se identificam e lutam pela mesma causa, se unissem virtualmente para mobilizar, disseminar informações e lutar pelos diversos direitos dos cidadãos.

A internet e as mídias digitais possibilitam uma nova compreensão e sentido para a participação, para a democracia, para o ativismo e para as identidades coletivas. A partir das ferramentas web 2.0, caracterizadas pela interação e colaboração, é possível participar de ações sociais coletivas de modo online e off-line (ROTHBERG; LUVIZOTTO; VANZINI, 2014): online, uma vez que a estrutura de conectividade da internet permite derrubar a barreira do tempo e do espaço, possibilitando a qualquer ator social se manifestar e deliberar sobre os mais diversos assuntos e contextos sociais. É possível fazer parte de grupos virtuais que possuam uma motivação, uma identidade coletiva e ali se auto representar, discutir, propor, aprender e organizar ações. O sujeito social pode participar de manifestações, atos, reuniões, assembleias e pode utilizar os recursos da internet para postar vídeos, fotos e todo tipo de conteúdo informacional em tempo real e tornar público aquele momento que somente os participantes presentes teriam condições de conhecer, mas com o uso da internet passa a ser de domínio público, instrumentalizando a participação político-social, notadamente a inclusão social das pessoas com deficiência.

Porém, para que haja uma sociedade verdadeiramente democrática, isto é, que realize o direito de todos, e não apenas da maioria, temos que concretizar com eficiência a tão almejada inclusão social. 


\section{A Inclusão das Pessoas com Deficiência na Sociedade da Informação}

O processo de globalização diminuiu sensivelmente a distância existente entre os países e aproximou as pessoas. Passamos, efetivamente, da era atômica à era digital ${ }^{4}$. Esther Morón descreve, com felicidade, esse atual fenômeno:

Para pode apreciar las ventajas y consecuencias de 'ser digital', aconséjase reflexionar sobre la diferencia entre átomos y bits. Como ya se afirmó, la mayor parte de la información nos llega en forma de átomos: libros, periódicos, revistas. El mundo es hecho de átomos. Un bit no tiene color, tamaño ni peso. Es el DNA de la información. Es tan solamente un número, cuya representación más elemental es una secuencia de ceros y unos. Los bits siempre fueron el elemento básico de la información pero en los últimos veinticinco años se han conseguido digitalizar cada vez más tipos de información, auditiva y visual, por ejemplo, reduciéndolos de igual manera a números.

Digitalizar significa convertir en números lo que se quiere transmitir. La digitalización permite que distintos tipos de datos y de información, como textos, voz e imágenes puedan convertirse en números, ser tratados del mismo modo y transmitidos por las mismas lineas. El fenómeno multimidia o hipermidia es el resultado de la digitalización de todos los tipos de señales.

La digitalización de la información es un concepto llave para entender las nuevas tecnologías y su generalización ha operado una división radical entre el analógico y el digital. El mundo digital es el mundo de la información convertida en dígitos y el mundo analógico es el restante. (MORÓN, 1999, p. 79).

Esse processo se deu tanto do ponto de vista econômico, como no setor de comunicação, principalmente, em razão da criação da internet. As barreiras físicas, culturais e econômicas que separavam as pessoas foram derrubadas pela internet, que possibilitou aos indivíduos que se encontravam geograficamente distantes se comunicarem rápida e facilmente.

Essa transformação nos meios de comunicação facilitou sobremaneira a concretização do direito fundamental à informação e ao conhecimento, possibilitando que a

\footnotetext{
${ }^{4}$ Observa, a propósito, Marco Aurélio Greco: "A atual revolução tecnológica pode ser resumida no reconhecimento de que estamos passando 'dos átomos para os bits'. O que isso significa? Os átomos serviam de meio físico para transporte e comunicação de mensagens no sentido de que 'contrato' tanto significava o vínculo jurídico como o documento redigido em papel (ou pergaminho) revestido de certas formalidades. Os átomos do papel eram o meio físico para transmitir a mensagem 'jurídica' da criação das relações, obrigações etc. Uma nova civilização está em criação; nesta, o conceito relevante não é mais o de átomo, mas sim o de bit, o que traz profunda alteração na estrutura das relações e na relevância dos projetos, pois a mensagem se desatrela do meio físico passando a ter vida própria independente de estar superposta a átomos" (Transações eletrônicas: aspectos jurídicos. Revista de Direito Bancário do Mercado de Capitais e da Arbitragem, São Paulo, RT, v. 8, p. 69, abr./jun. 2000).
} 
pessoa de sua própria casa ou usando o celular possa se conectar ao mundo. A velocidade da circulação da informação que a internet possibilitou foi outro fator preponderante para diminuição das barreiras. Desse modo, no que diz respeito à comunicação, houve uma mudança de paradigma, uma vez que as informações deixaram de ser transmitidas exclusivamente pela imprensa escrita, ou pelo rádio e televisão, e passaram a ser compartilhadas por milhares de pessoas por meio da internet.

A transição que vivemos é evidente. Como mencionamos, se a Revolução Industrial modificou as feições do mundo, a Revolução Digital está modificando nosso dia a dia. A diferença entre uma e outra está na velocidade surpreendentemente maior com que referidas transformações ocorrem durante a segunda. Enquanto na sociedade industrializada era a quantidade de trabalho investida nos produtos e serviços que servia de paradigma de valor, na sociedade digitalizada será a quantidade de informação e de conhecimento que tais produtos e serviços conseguirem agregar que determinará a formação do novo paradigma.

Surge, assim, uma nova era do desenvolvimento humano, baseada não só na valoração da informação, como no impacto das tecnologias sobre as relações sociais, humanas, empresariais, governamentais, entre outras.

A sociedade da informação pode ser compreendida como um ambiente que se apresenta no âmbito de um novo ciclo histórico posterior à pós-modernidade. A sua característica principal é exatamente a transformação sofrida nas sociedades contemporâneas, gerada pela revolução digital e pelo expressivo impacto da tecnologia, tanto nas relações humanas como nas relações empresariais, sociais e governamentais, contribuindo para o surgimento de complexas redes profissionais e tecnológicas voltadas à produção e ao uso da informação com potencialidade para gerar conhecimento, desenvolvimento e inclusão das pessoas com deficiência notadamente, quanto ao presente estudo, a acessibilidade digital.

Assim, não apresentamos um conceito fechado de sociedade da informação, a exemplo de Garcia Marques e Lourenço Martins (MARQUES; MARTINS, 2000, p. 43), ao mencionarem que a sociedade de informação - expressão que cada vez importa menos definir, na medida em que se vai vivendo em maior escala - assenta-se sobre o uso ótimo das novas tecnologias da informação e da comunicação, em respeito aos princípios democráticos, 
da igualdade e da solidariedade, visando o reforço da economia e da prestação de serviços públicos, e, afinal, a melhoria da qualidade de vida de todos os cidadãos.

Nessa linha, para que haja uma sociedade que concretize o direito de todos, e não apenas da maioria, temos que assegurar, com efetividade, a tão almejada inclusão social. Para que haja a verdadeira inclusão, deve ser contemplado o direito ao acesso das pessoas com deficiência ao meio digital.

Segundo Sassaki, a inclusão social pode ser conceituada como um processo pelo qual a sociedade se adapta para poder incluir as pessoas com deficiência e, simultaneamente, estas se preparam para assumir seus papeis na sociedade Consequentemente, a inclusão social é um processo de mão dupla, ou seja, tanto a pessoa com deficiência como a sociedade precisam se modificar. (SASSAKI, 1999, p. 41)

A Constituição Federal de 1988 não destoou dessa evolução que já vinha operando no mundo todo. Consagrou em diversas passagens a proteção da pessoa com deficiência, no sentido de assegurar a sua inclusão social. São reforçadas as normas que asseguram a dignidade da pessoa humana (artigo $1^{\circ}$, inciso III), a cidadania (artigo $1^{\circ}$, inciso I) e a igualdade (artigo $5^{\circ}$ ), seguidas por diversas leis protetivas que visam reconhecer a inclusão dessas pessoas na sociedade.

O Brasil, na busca pela concretização dos direitos das pessoas com deficiência, inclusive do direito à acessibilidade aos meios de comunicação e novas tecnologias, ratificou a já mencionada Convenção sobre os Direitos das Pessoas com Deficiência e seu Protocolo Facultativo, de 2007. Frise-se que esse foi o primeiro tratado de direitos humanos que cumpriu os termos do $\S 3^{\circ}$ do artigo $5^{\circ}$ da Constituição Federal de 1988, tendo status equivalente a emenda constitucional, como se observa do Decreto-legislativo 186/2008, que aprovou a norma internacional em questão.

A principal contribuição dessa Convenção é a positivação da mudança de paradigma da visão da deficiência no mundo, que passa do modelo médico, no qual a deficiência é tratada como um problema de saúde, para o modelo social dos direitos humanos, no qual a deficiência é resultante de uma equação que tem duas variáveis, quais sejam: as limitações funcionais do corpo humano e, no caso deste estudo, das dificuldades de participação da pessoa com deficiência ao ambiente digital. 
Todos os direitos garantidos pela Convenção sobre os Direitos das Pessoas com Deficiência, a partir desse novo paradigma positivado, têm o intuito de emancipar as pessoas com deficiência, permitindo o pleno gozo e o efetivo exercício de seus direitos e garantias fundamentais.

Tanto que, em seu preâmbulo, registra ser a deficiência um conceito em evolução e que resulta da interação entre as pessoas com deficiência e as barreiras ambientais que impedem sua plena e efetiva participação na sociedade em igualdade de oportunidades com as demais pessoas. Portanto, ao ter reconhecido que a deficiência é um conceito em evolução, constatou-se que essas pessoas têm capacidades e que, se elas tiverem informações e comunicações acessíveis, terão oportunidades de participação que até então não puderam vivenciar.

Assim, a Convenção, ao reconhecer o modelo social como o mais novo paradigma para conceituar as pessoas com deficiência, consolida a acessibilidade tanto como princípio, como direito. E, como princípio-direito, obriga os Estados à sua concretização como garantia fundamental, extremamente relevante para a concretização dos direitos humanos das pessoas com deficiência ${ }^{5}$.

Considerando a acessibilidade como condição de livre acesso, de aproximação, de utilização, do manuseio de qualquer objeto, local, ou condição, é seu objetivo proporcionar a todas as pessoas, e, principalmente às pessoas com deficiência, um ganho de autonomia e de mobilidade, para que possam usufruir dos espaços com mais segurança, confiança e comodidade. E para que isso ocorra, a Convenção determina que todos os ambientes eliminem as barreiras existentes, especialmente as que forem criadas pelo próprio ser humano, e que novos espaços sejam desenhados livres de barreiras, para não obstaculizar o pleno gozo e exercício dos direitos das pessoas com deficiência.

Portanto, a acessibilidade é a possibilidade e a condição de alcance, percepção, entendimento e interação para a utilização, a participação e a contribuição, em igualdade de oportunidades, com segurança e autonomia, independentemente de sua capacidade motora,

\footnotetext{
${ }^{5}$ Especificamente o disposto no preâmbulo da Convenção, alínea "v". Bem como o artigo $3^{\circ}$, "f", que define a acessibilidade como um dos princípios gerais a reger a Convenção. E no artigo $9^{\circ}$, trata da acessibilidade como um direito, inclusive obrigando os Estados a tomarem medidas apropriadas para assegurá-lo.
} 
visual, auditiva, intelectual, cultural ou social, a qualquer momento, em qualquer local e em qualquer ambiente físico ou computacional e a partir de qualquer dispositivo de acesso. Assim, a participação das pessoas em geral e das pessoas com deficiência em especial deve ser desenvolvido em ambiente acessível e inclusivo. Esse ambiente acessível é o propósito máximo da norma internacional, uma vez que ele, em suas concepções físicas (espaços arquitetônicos, mobiliários, equipamentos urbanos, transportes, informação e comunicação) e humanas (atitudes e procedimentos), é que permite (ou não) o exercício pleno e equitativo de todos os direitos, inclusive a acessibilidade ao ambiente digital.

Por ser um processo de transformação do ambiente e desenvolver-se a partir do reconhecimento social de que a deficiência é resultante do desajuste entre as características físicas, psíquicas ou sensoriais das pessoas e as condições em que elas atuam, a acessibilidade passa a ser retomada como um tema de grande importância para a vida em sociedade.

A acessibilidade, portanto, constituiu-se em direito instrumental, uma vez que sem acesso ao ambiente digital, por exemplo, as pessoas com deficiência não podem exercer, plenamente, a sua cidadania. Não há inclusão social e exercício da cidadania sem acessibilidade.

Para ter garantida autonomia e qualidade devida, a pessoa com deficiência necessita de recursos que aumentem, mantenham, ou melhorem suas capacidades funcionais; tais recursos podem também vir através de serviços e ou produtos denominados "tecnologia assistivas” ou ajudas técnicas. Para BERSH (2013, p. 2) o objetivo maior da tecnologia assistiva ou TA é proporcionar à pessoa com deficiência maior independência, qualidade de vida e inclusão social, através da ampliação de sua comunicação, mobilidade, controle de seu ambiente, habilidades de seu aprendizado e trabalho.

Portanto, a acessibilidade na web é a possibilidade e a condição de alcance, percepção, entendimento e interação para a utilização, a participação e a contribuição, em igualdade de oportunidades, com segurança e autonomia, em sítios e serviços disponíveis na $w e b$, por qualquer indivíduo, independentemente de sua capacidade motora, visual, auditiva, intelectual e cultural ou social, a qualquer momento, em qualquer local e em qualquer ambiente físico ou computacional e a partir de qualquer dispositivo de acesso. 
A presença da acessibilidade no meio urbano, bem como nas edificações, nos transportes, no trabalho e especificamente nesse estudo na informação e comunicação, e nas suas mútuas interações, é uma exigência constitucional. Surge, atualmente, de acordo com a Convenção sobre o Direito das Pessoas com Deficiência, como um direito forte, o que impacta na concepção contemporânea dos direitos humanos e impõe a sua releitura sob essa nova perspectiva.

Em consonância com esse direito fundamental ao acesso, a já mencionada Lei 13.146/2015, que institui a Lei Brasileira de Inclusão da Pessoa com Deficiência (Estatuto da Pessoa com Deficiência), traz avanços importantes quanto ao acesso das pessoas com deficiência no ambiente digital. Em capítulo reservado a acessibilidade em seu artigo 55, contempla que: "a concepção e a implementação de projeto que tratem de meio físico, de transporte, de informação e comunicação, inclusive de sistemas de tecnologias da informação e comunicação, e de outros serviços, equipamentos e instalações aberto ao público, de uso público ou privado de uso coletivo, tanto na zona urbana como rural, devem atender aos princípios do desenho universal, tendo como referência as normas de acessibilidade”.

Como se pode notar, a partir dos objetivos da denominada sociedade de informação, mostra-se, prontamente, o seu compromisso com a difusão e a integração das tecnologias de informação para a melhoria da qualidade de vida e para o crescimento sustentável da sociedade, bem como a inclusão da pessoa com deficiência no ambiente digital, em igualdade de oportunidades com as demais pessoas.

Percebemos que leis não faltam para assegurar às pessoas com deficiência o direito fundamental de acesso, todavia ainda não concretizado. Mas poderá se efetivar. E esse é o objetivo pretendido pela referida Lei Brasileira de Inclusão da Pessoa com Deficiência (Estatuto da Pessoa com Deficiência).

\section{Acessibilidade Digital para a Pessoa com Deficiência na Lei Brasileira de Inclusão}


A Agenda de Túnis da Cúpula Mundial da Sociedade da Informação, realizada em 2005, atribuiu à UNESCO um papel de liderança na implementação de ações para promover o acesso à informação e ao conhecimento. Nesse contexto, um resultado esperado é a inclusão digital e social de pessoas com deficiência, por meio da ampliação do acesso à informação em formato digital para a promoção de uma cidadania mais informada, educada e ativa (DEFOURNY, 2007).

Já que vivemos cada vez mais interligados pela internet, muitas vezes buscando trabalho, entretenimento, educação, comércio etc, a grande maioria dos sites não levam em consideração uma parcela importante dessa população. Segundo dados do IBGE (Instituto de Geografia e Estatística), através do Censo Demográfico realizado em 2010, verificamos que a população atual de pessoas com deficiências é de 45.623 .910 cidadãos, o que correspondente a 23,9\% da população brasileira atual e, de acordo com o mesmo órgão, cerca de 25 milhões de deficientes, apenas cerca de 10 mil ou mais têm acesso ao computador e à internet, o que é um número bem reduzido, mas que, se forem criadas e oportunizadas melhores condições de acesso, esse número poderá aumentar consideravelmente.

A Lei $\mathrm{n}^{\mathrm{o}} 13.146$ de 2015 é bastante didática e enfática ao dispor sobre a acessibilidade digital as pessoas com deficiência ou mobilidade reduzida. Tornou obrigatória a acessibilidade nos sítios da internet mantidos por empresas com sede ou representação comercial no País ou por órgãos de governo, para uso da pessoa com deficiência, garantindolhe acesso às informações disponíveis, conforme as melhores práticas e diretrizes de acessibilidade adotadas internacionalmente, sendo que os sítios devem conter símbolo de acessibilidade em destaque; dispôs que os telecentros comunitários que receberem recursos públicos federais para seu custeio ou sua instalação e lan houses devem possuir equipamentos e instalações acessíveis. Preceituou ainda, que os telecentros e as lan houses mencionados devem garantir, no mínimo, $10 \%$ (dez por cento) de seus computadores com recursos de acessibilidade para pessoa com deficiência visual, sendo assegurado pelo menos 1 (um) equipamento, quando o resultado percentual for inferior a 1 (um).

Determinou expressamente que as empresas prestadoras de serviços de telecomunicações deverão garantir pleno acesso à pessoa com deficiência, conforme regulamentação específica. Dispôs ainda, que caberá ao poder público incentivar a oferta de 
aparelhos de telefonia fixa e móvel celular com acessibilidade que, entre outras tecnologias assistivas, possuam possibilidade de indicação e de ampliação sonoras de todas as operações e funções disponíveis.

Em dispositivo que visa baratear o acesso à informação, preceituou que o poder público deve incentivar a produção, à edição, à difusão, à distribuição e à comercialização de livros em formatos acessíveis, inclusive em publicações da administração pública ou financiadas com recursos públicos, com vistas a garantir à pessoa com deficiência o direito de acesso à leitura, à informação e à comunicação. Para tanto, os editais de compras de livros, inclusive para o abastecimento ou a atualização de acervos de bibliotecas em todos os níveis e modalidades de educação e de bibliotecas públicas, o poder público deverá adotar cláusulas de impedimento à participação de editoras que não ofertem sua produção também em formatos acessíveis. Considerou que são considerados formatos acessíveis os arquivos digitais que possam ser reconhecidos e acessados por softwares leitores de telas ou outras tecnologias assistivas que vierem a substituí-los, permitindo leitura com voz sintetizada, ampliação de caracteres, diferentes contrastes e impressão em Braille. Por fim, dispôs que o poder público deve estimular e apoiar a adaptação e a produção de artigos científicos em formato acessível, inclusive em Libras.

Segundo a lei, as instituições promotoras de congressos, seminários, oficinas e demais eventos de natureza científico-cultural devem oferecer à pessoa com deficiência, no mínimo, os recursos de tecnologia assistiva. Os congressos, os seminários, as oficinas e os demais eventos de natureza científico-cultural promovidos ou financiados pelo poder público devem garantir as condições de acessibilidade e os recursos de tecnologia assistiva. Os programas, as linhas de pesquisa e os projetos a serem desenvolvidos com o apoio de agências de financiamento e de órgãos e entidades integrantes da administração pública que atuem no auxílio à pesquisa devem contemplar temas voltados à tecnologia assistiva.

Em capítulo específico, a LBI garante a Tecnologia Assistiva à pessoa com deficiência como sendo o acesso a produtos, recursos, estratégias, práticas, processos, métodos e serviços com essa tecnologia que maximizem sua autonomia, mobilidade pessoal e qualidade de vida. 
Mas como mencionamos anteriormente, é necessário que haja tecnologia assistiva adequada e adaptada as suas necessidades especiais, principalmente os deficientes visuais e auditivos, caso contrário, ficarão gravemente limitados quanto a quantidade e a qualidade de informações que podem acessar a internet, o que impediria que eles utilizassem de forma plena e autônoma as potencialidades deste meio de comunicação. Dentre as categorias de tecnologia assistiva, BERSH (2013, p.2) aponta recursos de acessibilidade ao computador como conjunto de hardware e software especialmente idealizado para tornar o computador acessível a pessoas com privações sensoriais (visuais e auditivas), intelectuais e motoras. Nestes dispositivos inclui os de entrada (mouses, teclados e acionadores diferenciados) e de saída (sons, imagens, informações táteis). Traz como exemplos desses dispositivos de entrada os teclados modificados, os teclados virtuais com varredura, mouses especiais e acionadores diversos, software de reconhecimento de voz, dispositivos apontadores que valorizam movimento de cabeça, movimento de olhos, ondas cerebrais (pensamento), órteses e ponteiras para digitação, entre outros. E como exemplos de dispositivos de saídas oftwares leitores de tela, software para ajustes de cores e tamanhos das informações (efeito lupa), os softwares leitores de texto impresso (OCR), impressoras braile e linha braile, impressão em relevo, entre outros.

Alguns órgãos internacionais coordenam e elaboração a padronização das regras de acessibilidade. O World Wide Web Consortium (W3C) é um consórcio internacional em que organizações filiadas, uma equipe em tempo integral e o público trabalham juntos para desenvolver padrões para a web. O W3C já publicou mais de cem padrões, como HTML, CSS, RDF, SVG e muitos outros. Todos os padrões desenvolvidos pelo W3C são gratuitos e abertos, visando garantir a evolução da web e o crescimento de interfaces interoperáveis. O W3C Brasil iniciou suas atividades em 2008 por iniciativa do Comitê Gestor da Internet no Brasil (CGI.br) e do Núcleo de Informação e Coordenação do Ponto BR (NIC.br). O W3C Brasil acompanha as discussões de alcance mundial sobre o desenvolvimento dos padrões, com uma atenção especial a temas como: Open Web Platform, dados abertos e acessibilidade na web além de contar com o Grupo de Trabalho de Acessibilidade na Web do W3C Brasil (GT Acessibilidade na Web), criado em março de 2012, o grupo se reúne periodicamente para planejar ações a serem realizadas no Brasil. Em 2013, o grupo 
contava com mais de sessenta pessoas, entre elas representantes do governo federal, estadual e municipal de diversos estados, membros de instituições para pessoas com deficiência, acadêmicos e representantes da sociedade civil.

Assim, para que a acessibilidade na web seja alcançada, a W3C-WAI identifica sete componentes:

1) Conteúdo é a informação contida numa página ou aplicação web, incluindo: -a informação natural, tal como texto, imagem e áudio; -o código ou marcação, que define a estrutura, a forma de apresentação, etc.

2) Navegadores são os tocadores de conteúdo multimídia e outros agentes do usuário.

3) Tecnologia assistiva é aquela usada por pessoas com deficiência e mobilidade reduzida, como é o caso dos programas leitores de tela, dos ampliadores de tela, dos teclados alternativos, entre outros.

4) O conhecimento do usuário, sua experiência e, em alguns casos, suas estratégias adaptativas para a utilização da web.

5) Desenvolvedores, designers, codificadores, autores, entre outros, incluindo pessoas com deficiência que são desenvolvedores e usuários que contribuem com conteúdo.

6) Ferramentas de autoria (authoring tools): softwares usados para criar sítios web.

7) Ferramentas de avaliação: avaliadores de acessibilidade, validadores de HTML, validadores de CSS, entre outros. (BRASIL, p. 24).

Esses componentes são essenciais e básicos para que os desenvolvedores de páginas possibilitem o acesso amplo e irrestrito à informação digital para as pessoas com deficiência, atendendo aos requisitos estabelecido na Lei n. 13.146. No entanto, como visto, incumbe precipuamente, ao Poder Público incentivar e criar políticas públicas que possibilitem essa acessibilidade digital da pessoa com deficiência e desse modo garantir que eles possam exercer em sua plenitude sua cidadania. A acessibilidade digital é importante para o exercício da cidadania e para a garantia do direito fundamental ao acesso à informação e a consolidação da democracia.

Dentro desse contexto, constatamos que o direito fundamental ao acesso à pessoa com deficiência, não só ao meio físico, ao transporte, mas, notadamente na informação e comunicação está amplamente assegurado em nosso ordenamento jurídico.

\section{Conclusão}


Vivemos numa sociedade baseada no desenvolvimento e na disseminação das tecnologias e da comunicação. O surgimento dessa nova sociedade trouxe, portanto, a necessidade de se repensar importantes aspectos relativos à organização social e o papel do Estado nesse novo contexto. Muitas ações de caráter político-social se fortaleceram e se potencializaram à medida em que a internet deu suporte a elas, utilizando sua arquitetura em rede para disseminar informação e promover a discussão coletiva. A partir dessa ferramenta foi possível propor e organizar ações e ampliar os canais de participação.

Avançando no processo de construção de uma sociedade que respeite a diversidade, foi aprovada com força de norma constitucional a Convenção dos Direitos da Pessoa com Deficiência e seu Protocolo Facultativo, cuja finalidade, não foi apenas de instituir novos direitos humanos e liberdade fundamentais para pessoas com deficiência, mas também em garantir que essas pessoas possam vir a desfrutá-los em igualdade de condições com todos os demais direitos sem discriminação. A regulamentação desse direito no âmbito interno se deu pela aprovação pela Lei $n^{\circ} 13.146$, de 06 de julho de 2015 que instituiu a Lei Brasileira de Inclusão da Pessoa com Deficiência (Estatuto da Pessoa com Deficiência).

A principal contribuição dessa Convenção e da lei que a regulamenta no Brasil é a mudança de paradigma da visão de deficiência no mundo, que passa do modelo médico, no qual a deficiência é tratada como problema de saúde, para o modelo social dos direitos humanos, no qual a deficiência é resultante de uma equação que tem duas variáveis, quais sejam as limitações funcionais do corpo humano e as diversas barreiras impostas pelo ambiente digital ao indivíduo.

O direito à acessibilidade, e via de consequência à participação é, portanto uma exigência constitucional elevada ao patamar de direito fundamental notadamente para as pessoas com deficiência ou mobilidade reduzida. Tal direito foi amplamente assegurado em nosso ordenamento jurídico, o que por si só não assegura que essas pessoas possam realizar de modo pleno e irrestrito esse direito fundamental e compartilhar os aspectos positivos das novas tecnologias, sobretudo no campo das comunicações; é essencial que lhes assegure a capacidade de utilizar da internet, onde a facilidade, rapidez e supressão das barreiras geográficas tornam possível não só o acesso aos mais diversos canais potencializadores de conhecimento, mas também de convívio e lazer. 
Todavia, somente a normatividade desses direitos não é o bastante para garantir a implementação de ações para efetivar a acessibilidade de modo real e palpável às pessoas com deficiência ao universo digital. A informação está na internet, mas ainda não está acessível para todos. Acessibilidade é um processo em construção.

\section{Referências bibliográficas}

BERSH, Rita. Introdução à tecnologia assistiva. Porto Alegre, Rio Grande do Sul, 2013. Disponível em: http://www.assistiva.com.br Acesso em: 13 de abril de 2017

BORDENAVE, Juan E. Díaz. O que é participação. São Paulo: Brasiliense, 1983.

BRASIL. Cartilha de Acessibilidadae na Web do W3C Brasil - Fascículo I - Introdução, p. 24

DEFOURNY, Vincent. Apresentação da obra: Inclusão digital e social de pessoas com deficiência: textos de referência para monitores de telecentros. - Brasília: UNESCO, 2007.

DEMO, Pedro. Participação é conquista: noções de política social participativa. 3. ed. São Paulo: Cortez, 1996.

FONSECA, André Azevedo da. A comunicação nos movimentos sociais: do panfleto de protesto à educação para a cidadania. Espaço Acadêmico, no 126, novembro de 2011, p. 67-71. Disponível em: <http://www.periodicos.uem.br/ojs/index.php/EspacoAcademico/ article/viewFile/12748/8145>. 2011. Acesso: 27 jul. 2015.

GOMES, Wilson. Internet e participação política em sociedades democráticas. FAMECOS, Porto Alegre, n. 27, p. 58-78, ago. 2005.

GRECO, Marco Aurélio. Transações eletrônicas: aspectos jurídicos. Revista de Direito Bancário do Mercado de Capitais e da Arbitragem, São Paulo, RT, v. 8, p. 60-85, abr./jun. 2000. 
LEVY, Pierre; AUTHIER, Michel. As árvores de conhecimentos. São Paulo: Escuta, 1995.

LEVY, Pierre. As tecnologias da inteligência: o futuro do pensamento na era da informática. Rio de Janeiro: Editora 34, 1993.

O que é o virtual? São Paulo: Editora 34, 1996.

A ideografia dinâmica: para uma imaginação artificial? Lisboa: Instituto Piaget, 1997.

. Cibercultura. Tradução de Carlos Irineu da Costa. São Paulo: Editora 34, 2001.

- A máquina universo: criação, cognição e cultura informática. São Paulo: ARTMED, 1998.

A inteligência coletiva: por uma antropologia do ciberespaço. 3. ed. São Paulo: Loyola, 2000.

Filosofia world: o mercado, o ciberespaço, a consciência. Lisboa: Instituto Piaget, 2000.

A Conexão Planetária: o mercado, o ciberespaço, a consciência. São Paulo: Editora 34, 2001.

Ciberdemocracia. Lisboa: Instituto Piaget, 2003.

O futuro da internet. São Paulo: Paulus Editora, 2010.

. O fogo liberador. São Paulo: Iluminuras, 2007.

LUVIZOTTO, Caroline Kraus. Cidadania, ativismo e participação na internet: experiências brasileiras. Comunicação e Sociedade, v. 30, p. 297-312, 2016.

MACHADO, Jorge Alberto S. Ativismo em rede e conexões identitárias: novas perspectivas para os movimentos sociais. Sociologias. Porto Alegre, 9 (18), p. 248-285, 
2007.

MARQUES, Garcia; MARTINS, Lourenço. Direito da informática. Coimbra: Almedina, 2000 .

MORÓN LERMA, Esther. Internet y Derecho Penal: "hacking” y otras conductas ilícitas en la red. Revista de Derecho y Processo Penal, Pamplona, Aranzadi, n. 1, p. 1-147, 1999.

ROTHBERG, Danilo; LUVIZOTTO, Caroline Kraus; VANZINI, Kátia Viviane da Silva. As revoltas e seu impacto sobre a comunicação pública: o potencial do Observatório Participativo da Juventude. In: Liinc em Revista, vol. 10, nº 1, pp. 227-240, 2014.

SASSAKI, Romeu Kazumi. Inclusão: construindo uma sociedade para todos. 3. ed. Rio de Janeiro: Editora WVA, 1999.

SCHERER-WARREN, Ilse. Das mobilizações às redes de movimentos sociais. Sociedade e Estado, v. 21, n. 1, p. 109-130, 2006.

SERRA, Joaquim Paulo. Novos media e participação política. Observatorio Journal, v. 6, n. 2, pp. $127-155,2012$. 